\title{
SOME EXPERIMENTS AND OBSERVATIONS UPON TENDRILS AND VINES,
}

EVINCING A PRINCIPLE OF ATTRACTION WHICI GOVERNS THE DIRECTION AND INNATE MOTIONS OF PLANTS AND TREES DURING THEIR GROWTH.

[Communiented for the Boston Modicnl and Surgical Journul.]

TH: vines selected were those of the bell-neck squash. Observing a number of tendrils on a large, thrifty vine by the side of a stone-wall, pointing to some stems of high golden-rod and buckthorn branches, the stems und branches were cut away and others bent so that the tendrils most turn to nearly a right angle in order to curl around them. In twenty-four hours, the tendrils had all changed their direction, and most of them performed several gyrations around the stems and branches. Observing several tendrils pointing to stones in the adjacent wall, as if attracted there, a slate pencil was placed in contact with one of them, around which it soon coiled itself. Several nails were placed in contact with others, but owing, as was supposed, to their sharp corners, did not attract the tendrils. Diry stems invited the tendrils, but it was thought not quite so well as the green.

On a warm, rainy morning, a green leaf of the buckthorn, with the surface outward, was rolled up, and gently placed in contact with a long, straight tendril, and in fifteen minutes it had taken one turn around the leaf. This experiment was repeated eight or ten times, on other tendrils, with nearly the same result, the time varying not more than an hour. From two of the tendrils, the leaves were removed, and within an hour or two the tendrils straightened again, and appeared to be attracted to the bush to which they had previously pointed. The next morning they were found entwined around the branches to which they had pointed the night before. Some of the leaves were held in the hand, and the motion of the tendrils around them must have been as fast as the minute hand of a watch, though in other instances it was slower. The property of curling was much more manifest in some states or stages of growth of the tendril than in others. It appears to be most active when the tendril has nearly attained its full growth. When tendrils meet with nothing to clasp, they twist around themselves, and after this they seem to lose their affinity for other bodies, as they did not uncurl when other bodies were placed in contact with thern.

The closeness with which tendrils embrace stems and reeds, and the tenacity with which they hold on without the aid of much if any glutinous matter, evinces as strong a degree of attraction for other bodies as the experiments related. On an examination of vines, tendrils may be found twisted on stems and reeds, in directions entirely contrary to those in which they grow from the stems of the vine.

A wonderful manifestation of an attractive properly may he seen in the ivy, where the tendrils penetrate into the bark of trees, and the vines often grow under it so as to be lost sight of for some distance up the tree. In this instance botanists have said that the tendrils answer instead of roots for sustenance, but experiment proves the assertion erroneous.

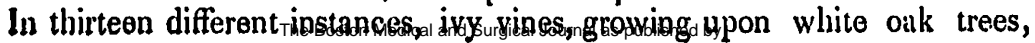


were severed or divided by cutting out sections, and leaving long stems above to grow or sustain themselves, if they would, by their tendrils; but in every case the vine died in an untsually short time-much quicker than mown grass. The leaves wilted in half a day. The same was the case with cucumber, squash, grape and beall vines. The close attachunent of ivy vines to trees and other vines, for the earth and other bodies, must, therefore, be ascribed wholly to a property of attraction which they have for bodies which will support them mechanically.

Vines possess this relative affinity or fellowship for other bodies as well as tendrils. This is abundantly manifest in the bean, grape, ivy, cucumber, and many other vines. Within what distances the principle operates, and with what force, is yet to be ascertained; but that such a property exists in living vegetables, there is as much evidence as of the force of gravitation.

In the inaterial world, we have already discovered several different species of attraction between bodies-capillary attraction, chemical attraction, attraction of gravitation, and cohesive, and magnetic attractions. Of their peculiar nature we know nothing. Their effects compose all our knowledge of them. There can be no surprise, therefore, in meeting with still another species of material affinity of a different nature.

We have given only one illustration of this undefined species of affinity. The vegetable world is fill of it. It is to the vegetable world what the power of gravitation is to matter in general. It is the great antagonist power to it, in every plant, tree, and blade of grass. When a young plant or herb first sprouts from the side of an old, exposed cellar wall, or walled up bank, the direction of it is perpendicular to the side of the wall or bank. But it never grows in this direction. It makes a right angle, or nearly one, and points to the zenith. 'The attraction of gravitation draws the plant or herb downward, and were there no other opposing force would bring the top to the ground; but the affinity which the leaves, flowers and stems have for the heat and light of the sun, overcomes the force of gravity or weight of the plant, and attracts it into the most favorable direction to receive the stimulus essential to its existence. The growth of the plant, acting alone, would send it in a direction straight from the wall or bank. The tree which grows upon the steep hill-side does not point in a direction perpendicular to the plane on which it grows, as its roots would seem to prompt it, but to the zenith whence comes the genial rays of the sun, obeying that impulsive affinity which it has for light, heat and air. If trees are prostrated by the wind or bent down by force, and life remains, all the new shoots grow in a direction perpendicular to the plane of the earth, or as nearly so as the attractions of cohesion and gravitation will allow. In trees already wooded and plants hardened and stiffened by growth and age, the affinity for light and heat is overcome. It is in the green, infantile, flexible state of the plant that the direction is determined by its affinity for heat and light. The leaves seem to perform the chief agency in the direction of plants. Their surfaces are ever drawn upward. Look at the grape vine, or the greenbriar, where the vine in one place hangs down, and in others ascends, and you will see the leaves completely 
The roots of trees are endowed with a like affinity for earth, water and nutriment. They secure plants and trees in the direction given them by the tops and leaves. This principle should be denominated THE ATTRACTION OF SENSATION, OR SENSITIVE ATTRACTION. It is visible in the stamens and pistils, in the calyxes and corellas. Overcome by gravity, it allows the head of the lily to droop, and causes the rose to look upward. It directs the vine in its gyrations around the pole or tree, and determines the tall oak to aspire to the zenith.

This warm aspiration in plants for substances without them, partakes somewhat of living animal matter, while it holds an equal kindred with the inorganic world. It is not intelligence. It may be a species or semblance of sensation in unity with a species of chemical or physical attraction. Sensation is not intelligence, but only an element or condition of it. The nature of the property or attribute is not material, its effects only are necessary to be known.

Betwern the germs and pollen of plants the manifestation of this principle is truly wonderful. The pistils of white and tiger lilies are an inch or two inches in length, and the pollen is attracted through this capillary vessel to the germ. The pistillate organs of Indian corn are twelve and often eighteen inches in length. The pollen is drawn through the wliole length of these silky vessels. The principle is as clearly demonstrated in living vegetables as the law of gravitation in falling bodies.

Tendrils and vines embrace and hug the staves they need for support. Only strew the seeds of plants and trees upon the naked earth, and roots dive into the matemal bed and creep in various and opposite directions in quest of sustenance, and fresh footholds to support the stems. The surfaces of leaves twist and turn to the sun's rays, the better to drink in the fiery element which they want for their functional use. The flower-cup and the flower cover imperviously the pistuls and stamens in their nassent state, but as soon as the organs of renewal are matured, the sepals and petals are attracted away, or inverted, by a superior affinity for the sun's rays. The quiescent germ expands into fruit, which sucks the rich juice from the maternal veins, and fattens on the element to which it holds an inborn affinity. The sap itself, obedient to the same law, tiaverses the capillary vessels of the tallest trees, and descends in a new form to barden into wood. There can be no impropriety, therefore, in defining the principle, the attraction of sensation, or sensitive attraction.

Providence, Sept. 7th, 1849.

\section{PARALLEL PASSAGES ON THE fUNGOUS THEORY OF EPIDEMICS.}

[Coinmunicated for the Bonton Medical and Burgical Journal. I

ON the 5 th September, 1845, there appeared an article in this Journal on the fungous origin of fever, by W. C. Wallace, M.D., of New York. The same views were published in 1846 in the report of the coinmittee appointed by the Legrislature of New York to investigate the Quarantine 